\title{
Language Maintenance and Core Values among Second Generation Arabs in the USA
}

\author{
Mona Turjoman \\ Dept. of English Language and Literature, College of Arts, King Saud University, Saudi Arabia \\ E-mail: mturj@ksu.edu.sa
}

Received: 08-11-2016

Published: 01-05-2017
Accepted: 11-01-2017

doi:10.7575/aiac.ijalel.v.6n.3p.94
Advance Access Published: March 2017

URL: http://dx.doi.org/10.7575/aiac.ijalel.v.6n.3p.94

\begin{abstract}
This sociolinguistics study investigated the maintenance of the Arabic language among three migrant Arab Muslim families, who have been living in the USA for at least ten years, particularly among the children. Each family has children between the ages of 10 to 15 and they attend American public schools. Arabic is essential in the religious rituals of the Muslim society. Yet living in an English-speaking environment makes it challenging for these families to maintain fluency in Arabic and English. The families live in Muncie, Indiana where the only means of formal teaching of Arabic is through a Sunday school held in the Mosque and parental attempts to teach them at home. Data were collected by using semi-structured interviews and participant observation over a six-month period and analyzed according to Smolicz's (1981) Core Value theory. The findings of the study indicated that all three families are aware of the challenges of maintaining the Arabic language and therefore emphasize the use of Arabic at home, to supplement the Arabic lessons in the Sunday school.
\end{abstract}

Keywords: sociolinguistics, language maintenance, Arab Americans, core value, Arabic

\section{Introduction}

The topic of language maintenance has been a major concern for linguists for the past few decades due to its importance in language loss or maintenance among different language communities, particularly when diasporas began to form in many parts of the world. These groups of people bring and maintain their own respective cultures, values and languages to their new settlements, while at the same time absorb and adjust to the new culture they find themselves in. Sociolinguistic researchers are particularly interested in the factors that influence language maintenance, attitudes of parents and children towards their heritage language and the stages of shift from the mother tongue language to the dominant language.

Being a minority in the new host country, although Arabs face a challenge to maintain the Arabic language, the challenge becomes even greater when they reside in a small city with neither a large Arab community nor Arabic schools. The number of domains of speaking their mother tongue decreases drastically, as they find themselves in more and more situations where English is the norm.

This paper investigates the Arabic language maintenance of three Arab families who are first generation immigrants to the United States (US) across the generations. The families all reside in Muncie, a small city in Indiana for the last ten years, with some even longer. Based on the Core Value Theory, the purpose of this study is to analyze their attitudes towards Arabic and what measures they take to maintain the language within their community.

\subsection{Background}

Muncie, Indiana is a small city located in east-central Indiana with a population of about 70,085 (United State Census 2010). According to the Zipatlas (http://zipatlas.com/us/in/city-comparison/percentage-arab-population.htm), the current population of Muncie is 94,866 and Arabs comprise 170 of Muncie's population. At least 150 of these Arabs are Muslims (President of Islamic Center of Muncie). Although there are about 350 Muslims in Muncie altogether, the majority are non-Arabs and non-Arabic speaking as well. Many of the Arabs are there on a temporary basis for educational purpose, while the minority, about 60, (President of Islamic Center of Muncie) are Arab Americans who are permanent residence in Muncie. These Arabs are mainly from Syria, Jordan, Egypt, Iraq and Libya. These residents are either first or second generation immigrants. Most of the parents of these families work, but at home with their families, they make an effort to maintain the Arabic language, since they still recognize it as their heritage language that gives them a sense of identity and links them to their homeland as well as to Islam, their religion. Islam is accepted throughout the Muslim world as a religion that is handled by the Arabic language, also the language of the Quran.

All the families under study are Muslims. As Muslims, they are required to read the Quran, the Holy Book for Muslims which is in Classical Arabic. Thus, Muslims must learn Arabic to be able to read the Quran. Unfortunately, there are no official Arabic schools in Muncie. Many of the Muslims rely on Arabic Sunday school run by volunteer members of the Muslim community in the Mosque, since it deals with the teaching of Islamic studies along the Arabic language. 
Volunteers teach the children basic Islamic teachings, the Arabic language and Quran reading. Due to the importance of the Arabic language to Islam, these families feel obligated to maintain it by re-enforcing its use at home. This in itself also becomes a challenge in the case where the children go to American public school and both parents are busy with jobs.

The language of the Quran is the Classical Arabic, as mentioned, or what is sometimes referred to as Modern Standard Arabic (MSA), and is "... generally used by the language of education, media, government, and business interaction" (Bale, 2010:134). Colloquial Arabic is the everyday used spoken variety. But it is worth mentioning that based on the many countries that have Arabic as their native language, there are numerous dialects in each country. In fact, Bale noted that "Arabic is not native to one particular country but rather, to a region of over 20 sovereign states and contested territories. Even within many of these states, it is not the case that their population speak one standard form of Arabic. Instead, regional and dialectal varieties of Arabic add to a standardized form of the language...." (127). The challenge to maintain the Arabic language for the Muncie families thus becomes much more extensive when the spoken variety of Arabic is different between community members due to the diversity of Arab families and to the fact that the spoken variety differs from the formal variety.

\subsection{The Core Value Theory}

The Core Value Theory was developed by Smolicz (1981) during his investigation of multilinguals in Australia to explain why certain communities want to maintain their language. Core value refers to "values that are regarded as forming the most fundamental components or heartland of a group's culture, and act as identifying values which are symbolic of the group and its membership" (Smolicz, 1999:105). Thus, different ethnic groups have different core values such as family for Italians, language for Greeks and religion for the Irish. Smolicz continues by stating that “...some ethnic groups are very strongly language-centred, so that their existence as distinct cultural and social entities depends on the maintenance and development of their ethno-specific tongues" (78).

Arab Muslims basically identify themselves through their religion, which is linked to the Arabic language and thus to their home country. Thus, these Arabs consider the Islamic religion and the Arabic language their core value. A Muslim is required to develop the Arabic language to perform religious duties. Gagonas (2011) stated that "when language is closely intertwined with other core values, such as religion, the match between attitudes and actual maintenance is even higher, whereas when the language is isolated from other cultural aspects, the match is lower". Since we have two core values attached to the Arab community under study, there should be a match in attitude and the maintenance of the Arabic language should also be higher.

This qualitative study investigates the participants' attitudes towards maintaining the Arabic language as a core value. The study also examines the measures that were taken by each family and family member to maintain the Arabic language. Therefore, participants were observed during a six months period and were interviewed individually to confirm the findings.

\section{Review of the Literature}

Language maintenance has not only been an interest to linguists, but also a great concern due to the fact that by the third generation, there is often a complete shift from the heritage language to the dominant language in migrant families (Fishman, 1991). Studies of Arabic language maintenance in the United States and other parts of the world were conducted on minority groups and reviewed in the following paragraphs.

Al-Sahafi (2015) investigated the role ten Arab Muslim immigrant fathers play in maintaining the Arabic language in their children in Auckland, New Zealand. Although the fathers come from different Arab countries, Al-Sahafi, indicated that the Arabic language unites them as a core cultural value. The subjects all seem to agree on the importance of maintaining the heritage language for reasons such as religion, family and ethnicity and set certain language usage policies at home. They also ensure social gatherings with homo-ethnic groups. In addition, they provide Arabic literacy material at home. Gomaa (2011) studied five Egyptian families residing in Durham, UK and their desire to transfer Egyptian Arabic to their children. The results of the study show that all the families regard Arabic as a culture core value that is closely related to religion and identity. In their study, Al-Sahafi and Barkhuizen (2006) investigated Arabic language use and proficiency of 63 Arab immigrants in Auckland, New Zealand. The findings show that participants over the age of 35 have more confidence in speaking Arabic and are more literary proficient than the younger participants. Gogonas (2011) examined language maintenance and shift of second generation Arabs living in Athens, Greece. The participants, who are mainly from Egyptian origin, are either Muslim or Coptic. Results of the study show that, for both groups, religion is the core value rather than language. But, while Copts are more willing to integrate in the Greek society, Muslims are not.

In the United States, the maintenance of the Arabic language has also gained research interest. Bale (2010) provided a full history of Arab immigration with a clear view of Arabic language maintenance and practice and the demography of Arab American communities in the US. Bale also gave a prediction of Arabic language maintenance based on historic and demographic facts. He stated that Arabs are aware of the importance of maintaining their language and "in the United States concerns and efforts of the US government itself is promoting the (Arabic) language" (Bale, 2010:131). A study on the role of mothers in maintaining the Arabic language among Arab immigrants in Chicago was investigated by Turjoman (2013). The result of the study indicated that mothers play a major role, which by far, surpasses the role of fathers in efforts to maintain the Arabic language. She also indicated that factors such as age, education and length of residency have a significant impact on the mothers' role in maintaining the Arabic language. In his study, Sehlaoui 
(2008) emphasized the importance of preserving the heritage language and gave an overview of Arabic teaching in the US based on the attention it was given by the educational community and the federal government post $9 / 11$. As a result, Arabic is not only taught at college and university levels, but also grade schools in 18 states. Rouchdy (2002) studied Arab Americans in the Detroit metropolitan area, which constitutes the largest Arab American population in the United States. She basically investigated the changes that the spoken language of Arab Americans has undergone in the Detroit area. She identified three groups of Arab speakers: those who only speak Arabic and live in Arab inhibited areas and who have created a pidgin English, those who only speak English and have very limited Arabic vocabulary and those who are bilingual. She concluded by stating that “... there will always be skill attrition in the Arabic spoken in the Diaspora because of constant contact with a dominant language. However, when skill attrition occurs, it is only in the immigrants' linguistic repertoire and such attrition can easily be reversed for the language to be learned" (Rouchdy, 2002:146).

Although these studies investigated the maintenance of the Arabic language among large congested Arab American communities in the United States, none of them explored language maintenance in small cities like Muncie. The Arab population in smaller cities is often without support of fellow Arabs who can contribute to the maintenance of culture and language. They, therefore, find themselves in a much more precarious world of losing their heritage and due to this fight to maintain them as much as they could.

\section{Method}

\subsection{Methodology}

Linguistic ethnography methods were used to collect data for the present study. According to Rampton et al., (2004, p. 2), linguistic ethnography states that "language and the social world are mutually shaping, and that close analysis of situated language use can provide both fundamental and distinctive insights into the mechanisms and dynamics of social and cultural production in everyday activity." The methods used for the present study included participant observation and informal semi-structured interviews with the parents and children individually over a period of six months. As an Arab who graduated from Muncie, it was feasible for the researcher to collect the data for the present study. All three families of the study are close friends with the researcher's family. Thus, interviews were conducted in informal settings in the participants' homes. Consent was obtained from all family members to record the interviews. Although participants were given the option to be interviewed in Arabic or English, all the parents chose to speak in Arabic, while the children chose English. However, both groups code-switched relatively easily between the two languages.

\subsection{Participants}

The three families that participated in the current study were originally from Syria, Libya and Iraq, respectively. All families have children born in their homeland. The family from Syria has a daughter and a son who was twelve and 14 years old, respectively, at time of study. The father was 37 years old with an MD degree and worked as a general physician, while the mother was 31 years old and was a sit home mom although she has a Bachelor's degree. The Libyan family has two daughters aged 15 and 10. The father was 34, has a Bachelor's degree and worked as a gas station attendant. The mother was 32, has a Bachelor's degree and was a baby sitter at home. The third family was from Iraq and has three children: a 13-year old daughter and two sons, 15 and 11. The father was 36 years old, has a Bachelor's degree and worked in general maintenance. The mother was 33, has a Bachelor's degree and was a cashier. Due to their employment status, the families are of different socio-economic backgrounds.

\subsection{Procedure}

Data collection was based on participant observation, and interviews, there were extensive visits to the three families' homes over the six-month period. During these visits the researcher observed the language used by the parents with each other, the children with their parents and the siblings with each other. During observation, the researcher took notes to keep track of the family communication system. Interviews were performed individually with each participant and recorded for accuracy of information.

\section{Results}

The aim of the study is to identify what, if any, practices of formal teaching of MSA was initiated, and to see if on the family and community micro-level the members of each family make an effort to speak Arabic. Although, as mentioned earlier, the MSA is different than the colloquial Arabic, parents in the current study believed that speaking to their children in Arabic will reinforce the sense of identity and culture awareness. They are all aware of the challenges and obstacles that they must cross to maintain the Arabic language. The practices of each family to maintain the Arabic language are analyzed separately in the subsections that follow.

\subsection{Bashar's family}

This Syrian family immigrated to the US ten years ago. Bashar is a medical doctor and works in the only local hospital in Muncie. His wife, Sawsan is a stay-at-home mom. Their two children, Rami and Samar are in Grades 8 and 5 , respectively, in an American public school.

During my observation of Bashar's family, I noticed that Sawsan has a fixed schedule during the week days. After the children come home from school, which is around three o'clock, they are given free time for about an hour. Then, Sawsan sets two hours daily for formal teaching of the Arabic language using Arabic textbooks from Syria. She also orders additional material online. On weekends, Bashar's family congregates with other Arab families who have children of the same age range. On Sunday, the children attend Arabic Sunday school at the mosque for 4 to 5 hours 
where Sawsan volunteers as a Quran teacher. The family also subscribes to Arabic TV programs. Both educational and entertaining Arabic programs use MSA. Bashar's economic status permits visiting family in Syria every year. Sometimes, the children's grandparents visit them in Muncie. This increases their opportunity to practice Arabic with people other than those in Muncie.

The parents speak to each other, as well as with their children in Arabic. Sawsan says: "if they speak to me in English, I say, 'what?' in Arabic and they repeat it in English. I am very strict about it. Sometimes while they are speaking in Arabic, they use English. But it is getting more difficult for them to speak Arabic, especially for Rami. He is part of the school football team and now spends a lot of time in practice and with friends where, of course, he talks English." The siblings seem to shift back and forth from English to Arabic while speaking to each other. When asked about his attitude in regards to the importance of maintaining the Arabic language, Bashar states: "Teaching my kids Arabic is important to me, but because I work long hours, I don't have time to teach them Arabic. That's why me and my wife decided that she stays home and focuses on teaching them." The children themselves understand the importance of the Arabic language, but state that it is difficult to speak Arabic all the time. Samar was only two years old when the family immigrated to the US but her mother, Sawsan taught her Arabic until she was of school age, and she joined her brother in the Arabic routine schedule. The demographics of Bashar's family are summarized in Table 3.

Table 1. Bashar's Family

\begin{tabular}{llll}
\hline Syrian Family & Age & Education & Job \\
\hline Father (Bashar) & 37 & MD & GP \\
\hline Mother (Sawsan) & 31 & BA & - \\
\hline Rami & 14 & $8^{\text {th }}$ grade & - \\
\hline Samar & 11 & $5^{\text {th }}$ grade & - \\
\hline
\end{tabular}

\subsection{Omar's family}

Omar's family began their life in the US as refugee immigrants. They have been living in Muncie for the past ten years. Omar has a BA degree and works long hours as a gas station attendant. His wife, Areej, works as a babysitter at home. She mainly babysits children of Arab families. Their two daughters, Basma and Reem, attend the same American public school. Due to their economic situation, both parents are required to work. Areej states that: "Reem was one year old when we came to the US, so I could not work because I didn't have any place to keep her. So, I decided to work as a babysitter so I can make money and care for Reem at the same time." Basma was already of school age when they arrived and enrolled in school immediately. Like Samar, Reem stayed at home until she was of school age and was also taught Arabic by her mother and is therefore, much more fluent in Arabic than her sister Basma. The parents both agree on the importance of transmitting the Arabic language to their daughters for religious and cultural purposes. However, it is Areej who manages the teaching of Arabic to her daughters. Areej says: "By the time Omar gets home, he just wants to eat and sleep so I have to take care of teaching the girls Arabic." She gets some teaching material from the mosque and online. She also reads Arabic bedtime stories to her children. Sehlaoui (2008: 288) states that "children must be read to regularly in the heritage language from a very young age." But, due to the nature of her job, she does not spend as much time as she would like teaching her daughters Arabic, but she does take them to the Arabic Sunday school regularly. Both the children are aware of the importance of Arabic to their religion as well as their sense of identity. Reem states the following: "I am an Arab and a Muslim so I need to know Arabic to pray."

Both parents speak to each other and to their children in Arabic. As for the children, they usually reply to their parents in English. The siblings, speak to each other, mainly in English. They watch English programs on TV and have no access to Arabic channels due to their economic situation. Because of political reasons, they are also not able to visit family in Libya. Table 2 summarizes the demographics of Omar's family.

Table 2. Omar's Family

\begin{tabular}{llll}
\hline Libyan Family & Age & Degree & Job \\
\hline Father (Omar) & 34 & BA & Gas station attendant \\
\hline Mother (Areej) & 32 & BA & Babysitter \\
\hline Basma & 15 & $9^{\text {th }}$ grade & - \\
\hline Reem & 10 & $5^{\text {st }}$ grade & - \\
\hline
\end{tabular}

\subsection{Samir's family}

Samir's family came to the US 10 years ago when their youngest child was only two years old. Samir, had an Iraqi father who passed away in Iraq the year he brought his family to the US. His mother is a non-Muslim American, who came to the US with them. She speaks a little Arabic but not enough to carry on full conversations. Samir works as a 
maintenance man in a hotel in Muncie. He is bilingual due to his parents' mother tongues. Suha, Samir's wife, works as a cashier in a department store. Their three children, Hasan, Zahra, and Ali are all enrolled in American public schools.

This family seems to be the most complicated when it comes to Arabic language maintenance. Since Samir's family was living with his parents in Iraq, his children were brought up as bilinguals because they were living with his mother, who is an American. But, after they moved to the US, there was an immediate language shift towards more English. When Samir and Suha are at work, the children are left with their grandmother who tries to speak to them in Arabic based on their parents' request. But because of her limited Arabic proficiency, she frequently switches to English. Although the family has both English and Arabic TV programs, they prefer watching English programs.

Both Samir and Suha participate in teaching their children Arabic. They take their children to the Arabic Sunday school, where they are both volunteer teachers. When Samir and Areej speak to each other and to their children, they use Arabic, but when Samir talks to his mother, they code-switch between Arabic and English. Areej says: "I make sure I speak Arabic to my mother-in-law because I tell my children to speak to her in Arabic." The children seem to speak mostly English, and they rarely code switch between Arabic and English when speaking to each other, but are fully aware of the importance of maintaining the Arabic language. Zahra states the following concern: "Learning Arabic will make me a better Muslim." Suha, on the other hand, complains that "Hasan goes out with his friends who are American, and he joined the Science Club at school so he hardly uses Arabic anymore." The demographics of Samir's family are summarized in Table 3.

Table 3. Samir's Family

\begin{tabular}{llll}
\hline Iraqi Family & Age & Degree & Job \\
\hline Father (Samir) & 36 & BA & Maintenance man \\
\hline Mother (Suha) & 33 & BA & Cashier \\
\hline Hasan & 15 & $9^{\text {th }}$ grade & - \\
\hline Zahra & 13 & $7^{\text {th }}$ grade & - \\
\hline Ali & 11 & $5^{\text {th }}$ grade & - \\
\hline
\end{tabular}

In addition to the measures that the parents of the current study take to maintain the Arabic language, they have family gatherings, if not every week then every other week with other Arab families. Rouchdy (2002:134) observed this to also be true when he stated that "... whenever possible, Arabs still congregate and establish specific speech communities whose members share common linguistic, social and cultural features." These gatherings seem to play a major role in maintaining the Arabic language and reinforcing self-identity.

\section{Discussion}

It seems that the maintenance of the Arabic language faces new challenges every day in the Arab diaspora. The participants in the current study are all aware of the importance of maintaining the Arabic language but certain factors make it difficult to fully transmit the heritage language to the second generation due to the interference of the dominant host language. Based on the results of the study, there are four major challenges that the participants of the study face.

First, the Arab population in Muncie, Indiana is small and the majority of them are there on a temporary basis, as mentioned earlier. This makes it difficult for the families to form long lasting relationships with each other, especially the children. Nesteruk (2010: 284), reached the same conclusion in her study of Eastern Europeans residing in the USA. The researcher states that there is "... a positive association between immigrants' language maintenance and the number of contacts in their social network who speak the heritage language." In addition, when new Arab families arrive in Muncie, the permanent Arab Americans seem to recognize a difference between them and the new arrivals (Abraham \& Abraham, 1983). Arab Americans seem to be more integrated in the American community and the new Arab arrivals are not there long enough to integrate. It should also be noted that whenever there is a large Muslim community, the situation vicissitudes, like the case where Egyptians residing in Greece consider religion and not language as their core value, as noted by Gogonas (2011:20) that "Muslim Egyptian pupils are dominant bilingual in Arabic and are more literate in Arabic than Coptic Egyptians."

Second, due to the small Arab American population in Muncie, Indiana, there are no Arabic schools or public schools that offer Arabic as a first or second language. Since all the children, of the present study, attend American public schools, and inevitably are exposed to the English language for many hours each day not only at school, but in many interactions of their everyday life, it is not surprising that they will eventually find it more salient to use English than Arabic. These children immigrated to the US when they were at a young age, and although the parents make efforts to transmit Arabic to them, they live in an English-dominant society where they deal with English throughout the day. Although the US government funds and promotes Arabic learning (Bale, 2010; Rouchdy 2002; Sehlaoui, 2008), it is only cities that are with concentrated Arab population that enjoy the facilities, such as Detroit, New York, Los Angeles, Chicago, and Washington DC (Sehlaoui, 2008).

Third, the older boys, Rami from Bashar's family and Hasan from Samir's family are both involved in extra-curricular activities in school. Therefore, they spend more time using English with their American peers. This in itself is a great 
challenge because "...adolescents tend to move the center of their social life from family to friends and school" (Pauwels, 2005). This is supported by Al-Sahafi and Barkhuizen's (2006), study where English becomes the dominant language in public domain for the younger participants. In contrast, Park (2011) found that Korean ethnic churches in Montreal develop Korean-Canadian students' literacy skills in Korean through religious activities and teachings, all in the efforts of maintaining the mother tongue.

Finally, the majority of the Muslim community in Muncie are non-Arabs and non-Arabic speakers. They know Arabic enough to conduct religious rituals but not for daily spoken communication and interaction with Arab speakers. Although the Muslim community arranges numerous activities for Muslim children, alongside the Arabic Sunday school, because the majority of these Muslims come from different parts of the world, the English language is the median of communication between members. Similarly, the American Hindu community is also "facing a conflict of their two identities American and Hindu. Their American identity motivates them to accept English in the rituals in order to pass on their heritage to the next generation for whom English is the native language ... On the other hand, their Indian Hindu identity prevents them from replacing Sanskrit in fear of losing their Hindu identity," as found by Pandharipande (2013:426).

Although the Arab Americans in Muncie face the challenges mentioned above, the parents in the present study are well aware that they have to set more time and effort to transmit Arabic to their children. They clearly show the desire and commitment to maintain the Arabic language and culture among their family members. The parents speak to their children in Arabic and only respond in English minimally. In contrast, Tuominen (1999) in her study, found that it is the children who decide what language will be spoken at home. However, Pauwels (2005) stated that children "who are exposed to a CL (community language) in the home usually develop good receptive skills in the language even if their degree of active (productive) use is very limited." These parents also insure that their children attend Arabic Sunday school on a regular basis and those who have time, continue to teach the children Arabic at home. Earlier studies support these findings (Al-Sahafi, 2015; Gogonas, 2011; Turjoman, 2013).

\section{Conclusion}

The present study is the first of its kind to study Arabic language maintenance as a core value to Arab Muslim families who reside in a small community of speakers of Arabic in a small town, namely, Muncie, Indians. These families face bigger challenges than those Arab Muslims who live in big cities due to the fact that the number of Arabic-speaking Muslims is so small so they are not able to establish an official Arabic school. In addition, the majority of Muslims in Muncie are non-Arabs, so Arab parents and children have to use English as a means of communication during Muslim congregations. Not only that, the children in the present study all go to American public schools where they are exposed to only English. Thus, there is a great chance of shift from Arabic to English. But it is clear from the data that all three families under study consider the Arabic language as a core value that is strongly supported by the Islamic religion.

Although there is variation in the way that each family deals with maintaining the Arabic language, the religious basis is obvious by the efforts each family contributes to the process of maintaining the Arabic language in their children. Therefore, none of the challenging factors contribute to a complete shift or lose of the Arabic language. One of the reasons, as stated by Bale (2010:146), is that “...Arabic is a language native to over 300 million people in the Arab world. In addition, one billion people use Arabic for worship all over the world. Thus, Arabic is, and will be, a vital world language." There will always be some form of exposure to the Arabic language to the migrant Arabs. Moreover, "...the Muslim identity has created a special function for Arabic - a religious function-because only Arabic can be used to fulfill the obligation of the most important pillars of Islam, the prayer" (Rouchdy, 2002:143).

The three parents in the study were completely aware of the importance of maintaining the Arabic language and made an effort to achieve that goal. Sehlaoui (2008:287) noted the following concern: "Heritage language preservation starts at home. ...I make sure that my children speak Arabic at home and communicate with me in Arabic, which costs time, effort, and money." Pauwels (2005:124) emphasizes the role of family by stating that "the family is a crucial site of language maintenance... remains for most immigrants and their offspring the main domain for community language." It is also important to remember that these families left the place where Arabic was the dominant language and came to a place where it is the minority (Suleiman, 1999).

Although the study is context specific, it contributes to the study of Arabic language maintenance and cultural identity in the USA. It is unique in the sense that it is carried out in a small city where Arabs are a minority of the Muslim community. It also investigates language maintenance on the individual family level as opposed to the community level. The aim of the current research is to explore the attitudes of parents and their children's attitudes towards maintaining the Arabic language as a core value. It also considers the procedures that these families take to maintain the Arabic language.

Further study to investigate factors that may influence language maintenance, such as the political and economic situations of the families, gender and age difference would provide additional data that would better help linguists and sociolinguists understand the process of language maintenance.

A longitudinal study that tracks the development of the second generation speakers in their use of the Arabic language would also be useful to show if language maintenance has taken place or otherwise. 
Acknowledgement

This is a research project that was supported by a grant from the Research Center for the Humanities, Deanship of Scientific Research at King Saud University.

\section{References}

Abraham, S. Y. \& Abraham, N. (1983). Introduction. In S. Y. Abraham \& N. Abraham (Eds.), Arabs in the New World: Studies on Arab American communities (pp 1-7). Detroit, MI: Wayne State University.

Al-Sahafi, M. (2015). The Role of Arab fathers in heritage language maintenance in New Zealand. International Journal of English Linguistics, 5(1), 73-82.

Al-Sahafi, M. and G. Barkhuizen. (2006). Language use in an immigrant context: The case of Arabic in Auckland. New Zealand Studies in Applied Linguistics, 12(1), 51-69.

Bale, J. (2010). Arabic as a heritage language in the United States. International Multilingual Research Journal 4, 125151.

Fishman, J. (1991). Reversing language shift. Clevedon: Multilingual Matters.

Gogonas, N. (2011). Religion as a core value in language maintenance: Arabic speakers in Greece. International Migration. Blackwell Publishing Ltd.

Gomaa, Y. (2011). Language maintenance and transmission: The case of Egyptian Arabic in Durham, UK. International Journal of English Linguistics, 1(1), 46-53.

Nesteruk, O. (2010). Heritage language maintenance and loss among the children of Eastern European immigrants in the USA. Journal of Multilingual and Multicultural Developments, 31(3), 271-286.

Pandharipande, R. (2013). The language of Hinduism in the US diaspora. World Englishes 32 (3), 417-428.

Park, S. (2011). The role of ethnic religious community institutions in the intergenerational transmission of Korean among immigrant students in Montreal. Language, Culture and Curriculum 24 (2), 195-206.

Pauwels, A. (2005). Maintaining the community language in Australia: Challenges and roles for families. The International Journal of Bilingual Education and Bilingualism, 8(2\&3), 124-131.

Rampton, B., Tusting, K., Maybin, J., Barwell, R., Creese, A., \& Lytra, V. (2004). UK linguistic ethnography: A discussion paper

Rouchdy, A. (2002). Language conflict and identity: Arabic in the American diaspora. In A. Rouchdy (Ed.). Language contact and language conflict in Arabic: Variations on a sociolinguistic theme (p.133-148). London: Routledge/Curzon.

Sehlaoui, A. (2008). Language learning, heritage, and literacy in the USA: The case of Arabic.

Language, Culture and Curriculum 21 (3), 280-291.

Smolicz, J. J. (1981). Core values and cultural identity. Ethnic and Racial Studies, 4(1),75-90.

Smolicz, J. J., Secombe, MJ and Zajda, J. (1999). J.J. Smolicz on Education and Culture. Melbourne: James Nicholas Publisher.

Suleiman, M. W., ed. (1999). Arabs in America. Philadelphia: Temple University Press.

Tuominen, A. (1999). Who decides the home language? A look at multilingual families. Int'l J. Soc. Lang. 140, 59-76.

Turjoman, M. (2013). The Arabic language and the role of mothers in maintaining it among Arab family immigrants in Chicago. International Journal of Arts and Sciences, 6(3), 659-667. 